Research article

\title{
High expression of Lewisy/b antigens is associated with decreased survival in lymph node negative breast carcinomas
}

\author{
Zahra Madjd ${ }^{1}$, Tina Parsons ${ }^{2}$, Nicholas FS Watson ${ }^{1}$, Ian Spendlove ${ }^{1}$, Ian Ellis ${ }^{3}$ and \\ Lindy G Durrant ${ }^{1,2}$
}

\author{
${ }^{1}$ Academic Department of Clinical Oncology, Institute of Infections Immunity and Inflammation, University of Nottingham, City Hospital, Nottingham, \\ UK \\ 2Scancell Ltd, BioCity, Nottingham, UK \\ 3Department of Histopathology, City Hospital, Nottingham, UK
}

Corresponding author: Lindy G Durrant, lindy.durrant@nottingham.ac.uk

Received: 16 Apr 2005 Revisions requested: 17 May 2005 Revisions received: 25 Jun 2005 Accepted: 12 Jul 2005 Published: 28 Jul 2005

Breast Cancer Research 2005, 7:R780-R787 (DOI 10.1186/bcr1305)

This article is online at: http://breast-cancer-research.com/content/7/5/R780

(C) 2005 Madjd et al.; licensee BioMed Central Ltd

This is an Open Access article distributed under the terms of the Creative Commons Attribution License (http://creativecommons.org/licenses/by/ 2.0), which permits unrestricted use, distribution, and reproduction in any medium, provided the original work is properly cited.

\begin{abstract}
Introduction There is sufficient evidence that blood group related Lewis antigens are tumour-associated molecules. The Lewis $^{y}$ and Lewis ${ }^{b}$ antigens are complex carbohydrates that are over-expressed by breast, lung, colon and ovarian cancers. The $\mathrm{SC} 101 \mathrm{mAb}$ is a unique Lewis $/ \mathrm{b}$ binding antibody that binds to native and extended Lewisy and Lewis ${ }^{b}$ haptens, displaying no cross reactivity with $\mathrm{H}$ type $1, \mathrm{H}$ type 2 , Lewis ${ }^{\mathrm{x}}$ or normal blood group antigens.

Methods Immunohistochemical detection of Lewis ${ }^{y / b}$ was performed on 660 formalin-fixed, paraffin embedded breast tumour specimens using a streptavidin-biotin peroxidase technique. Tissue from these patients had previously been included in tissue microarrays. This cohort comprises a well characterized series of patients with primary operable breast cancer diagnosed between 1987 and 1992, obtained from the Nottingham Tenovus Primary Breast Carcinoma Series. This includes patients 70 years of age or less, with a mean follow up of 7 years.
\end{abstract}

Results Of the breast carcinomas, 370 of 660 (56\%) were negative for Lewisy/b expression, 110 (17\%) cases showed a low level of expression ( $<25 \%$ of positive cells) and only 54 cases $(8 \%)$ showed extensive expression of Lewisy/b $(>75 \%$ of positive cells). We found significant positive associations between histological grade $(p<0.001)$, Nottingham Prognostic Index $(p=0.016)$, tumour type $(p=0.007)$ and the level of Lewis $y / b$ expression. There was a significant correlation between the proportion of Lewis ${ }^{y / b}$ positive tumour cells and survival in lymph-node negative patients $(p=0.006)$.

Conclusion The unique epitope recognised by SC101 mAb on Lewisy/b hapten is over-expressed on breast tumour tissue compared with normal breast. In this large series of invasive breast cancers, higher expression of Lewisy/b was more often found in high grade and poor prognosis tumours compared to good prognosis cancers. Moreover, in lymph node negative breast carcinomas, over-expression of Lewis ${ }^{y / b}$ hapten was associated with significantly decreased patient survival.

\section{Introduction}

Blood group related antigens are frequently altered in association with neoplastic transformation [1-3]. Lewis blood group antigens Lewis ${ }^{a}$ and Lewis $^{b}$, and their positional isomers Lewis ${ }^{x}$ and Lewis $y$, are carbohydrate antigens. Lewisy antigen is a difucosylated oligosaccharide with the chemical structure Fuc $\alpha 1 \rightarrow 2$ Gal $\beta 1 \rightarrow 4$ [Fuc $\alpha 1 \rightarrow 3$ ] GlcNAc $\beta 1 \rightarrow R$, which belongs to the $A, B, H$, Lewis blood group family. The Lewisy antigen is expressed predominately during embryogenesis, and in adults expression is restricted to granulocytes and epi- thelial surfaces [4]. Over-expression of Lewisy has been shown in the majority of cancer cells derived from epithelial tissues, however, including breast, ovary, pancreas, prostate, colon and non-small cell lung cancers [5], either at the plasma membrane as a glycolipid or linked to surface receptors (e.g. of the E-rb-B family) [6].

The SC101/29 mAb is a unique Lewis $/ / b$ binding antibody that recognises both Lewisy and Lewis ${ }^{b}$ haptens [7]. It shows no cross reactivity with $\mathrm{H}$ type 1 or $\mathrm{H}$ type 2 , Lewis ${ }^{\mathrm{x}}$ or normal blood group antigens. This antibody binds strongly to a wide range of tumour tissues, including colon, gastric and ovarian 
Table 1

\section{Patient and tumour characteristics}

\begin{tabular}{lc}
\hline Tumour and patient characteristics & Proportion \\
\hline Alive & $86 \%(570)$ \\
Dead (of breast cancer) & $14 \%(90)$
\end{tabular}

Age (years)

$<40$

$9 \%(58)$

41-50

29\%(192)

51-60

$33 \%(221)$

$>61$

29\% (189)

Menopausal status ${ }^{a}$

Premenopausal

36\% (227/623)

Postmenopausal

64\% (396/623)

Histological grade

Grade 1

20\% (135)

Grade 2

33\% (215)

Grade 3

$47 \%(310)$

Lymph node status

Negative

$65 \%(427)$

Positive

35\% (233)

Nottingham Prognostic Index

Good

$35 \%(226 / 638)$

Moderate

52\%(332/638)

Poor

$13 \%(80 / 632)$

Tumour histological type ${ }^{b}$

Group 1

$5 \%(32 / 647)$

Group 2

$22 \%(142 / 647)$

Group 3

$12 \%(78 / 647)$

Group 4

$61 \%(395 / 647)$

Vascular invasiona

None or probable

$69 \%(444 / 643)$

Definite

$31 \%(199 / 643)$

Distant metastases

Absent

$85 \%(559)$

Present

$15 \%(101)$

Any recurrence

Absent

$74 \%(488)$

Present

$26 \%(172)$

Regional recurrence (axillary lymph node)

Absent

$91 \%(598)$

Present
Table 1 (Continued)

\section{Patient and tumour characteristics}

Local recurrence (in the breast)

Absent

$90 \%(591)$

Present

$10 \%(69)$

aPercentage of total number of recorded cases. ${ }^{\mathrm{b}}$ Tumour sections were classified into four prognostic type groups as previously described [26]: 1, excellent prognosis type ( $>80 \% 10$ year survival) includes tubulo-lobular, tubular, mucinous and invasive cribriform carcinoma; 2 , good types (60\% to $80 \% 10$ year survival) includes tubular mixed, mixed ductal with special type and alveolar lobular carcinoma; 3 , moderate prognosis types $50 \%$ to $60 \% 10$ year survival) includes classical lobular, medullary, atypical medullary and lobular mixed carcinoma; 4 , poor prognosis types $(\leq 50 \% 10$ year survival) includes ductal/NST, solid lobular, mixed ductal and lobular carcinoma.

and it may also show strong reactivity with a range of normal tissue expressing either Lewisy or Lewisb.

To our knowledge, there has been no previous study examining whether there is any prognostic significance of Lewis $/ / b$ expression in breast carcinoma. It was, therefore, of interest to determine the expression of Lewis $\mathrm{y} / \mathrm{b}$ in a large series of breast cancer tissue arrays using the SC101 mAb. Expression of Lewis ${ }^{y / b}$ was then associated with clinicopathological parameters and patient outcomes.

\section{Materials and methods}

\section{Patients and tumour characteristics}

The study group consisted of 660 primary operable invasive breast carcinomas from patients aged 27 to 70 years (median 54 years) diagnosed from 1987 to 1992 and obtained from the Nottingham Tenovus Primary Breast Carcinoma Series. Patient characteristics, including age and menopausal status, along with information on local, regional and distant recurrence and survival were retrieved from a prospectively maintained database. Patients and tumour characteristics are shown in Table 1. Patients were followed up at 3 month intervals initially, then every 6 to 12 months for a median period of 83 months, with a mean survival of 77 months (1 to 151 months). Ethical approval was granted by the Nottingham Research Ethics Committee.

This is a well characterized series of primary operable breast cancers treated in a uniform manner, and has been used to study a wide range of potential prognostic factors and markers. Tumour characteristics, including histological grade [8], tumour type [9], vascular invasion [10], menopausal status [11], tumour size, lymph node stage and Nottingham Prognostic Index [12] are routinely assessed and recorded in a prospectively maintained database. The Nottingham Prognostic Index (NPI) score was calculated for each patient based on the following equation:

$\mathrm{NPI}=0.2 \times$ tumour size $(\mathrm{cm})+$ grade $(1-3)+$ lymph node stage $(1-3)$ 
This index predicts survival of patients with invasive breast cancer and is used clinically to define three groups with either a good $(\mathrm{NPI}=\leq 3.4)$, moderate $(3.41<\mathrm{NPI} \leq 5.4)$ or poor (NPI $>5.4$ ) prognosis according to the score obtained. Patient management was based on tumour characteristics by NPI and hormone receptor status. Patients with an NPI score $\leq 3.4$ received no adjuvant therapy, those with a NPI score $>3.4$ received tamoxifen if estrogen receptor (ER) positive $( \pm$ Zoledex if pre-menopausal) or classical cyclophosphamide, methotrexate and 5-fluorouracil (CMF) if ER negative and fit enough to tolerate chemotherapy.

\section{Construction of the tissue microarray blocks}

At the time of resection, all tumours were managed in a standardised fashion, with immediate incision and fixation in neutral buffered formalin to minimize any diffusion problems, followed by processing through to embedding in paraffin wax. Breast cancer tissue microarrays were prepared as described previously [13]. Microarray samples with a diameter of $0.6 \mathrm{~mm}$ were punched from selected regions of each 'donor' block using a manual Tissue Arrayer (Beecher Instruments, Sun Prairie, WI, USA), and precisely arrayed into a new recipient paraffin block. These tissue microarray blocks were constructed in triplicate, at a density of 100 cores per block.

\section{Immunohistochemistry}

The SC101 mAb binds to native and extended Lewisy and Lewisb haptens [7]. Tissue microarray sections $4 \mu \mathrm{m}$ thick were cut and immunohistochemical staining was performed using a strepavidin-biotin complex (ABC) method as described previously [14]. Microwave pre-treatment was performed in citrate buffer $(\mathrm{pH} \mathrm{6.0)}$ for 10 minutes at high power followed by 10 minutes at low power to retrieve antigenicity. The primary antibody SC101 was incubated on the slides for $1 \mathrm{~h}$, at an optimal dilution found to be 1:1000 (stock concentration $1.1 \mathrm{mg} / \mathrm{ml}$ ). Negative controls, consisting of normal swine serum instead of primary antibody, confirmed the specificity of the staining. Sections from a colon carcinoma previously determined to express Lewis ${ }^{y / b}$ were used as positive control.

\section{Evaluation of immunostaining}

All immunostained tissue arrays were evaluated using a semiquantitative system (by ZM) after a series was examined on a double-headed microscope blinded to patients' outcome and other clinical and pathological parameters. The obtained results were confirmed by two observers (ZM and IOE) using a multi-headed microscope and, in difficult cases, a consensus was achieved. Two features were assessed, the intensity of staining and the percentage of cells stained. The intensity of the immunostaining was classified into four categories: 0 , no immunostaining present (as shown in Fig. 1); 1, weak immunostaining (Fig. 2); 2, moderate immunostaining (Fig. 3); and 3 , strong immunostaining (Fig. 4). The percentage of positive cells at each intensity was also assessed semi-quantitatively,
Figure 1

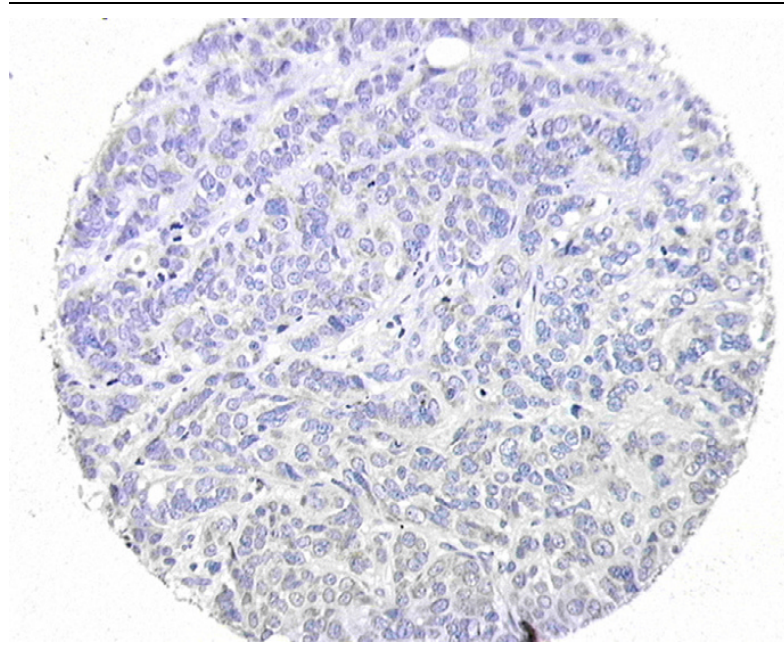

Tissue microarray core demonstrating tumour with absent Lewis ${ }^{y / b}$ expression. Fifty-six percent of breast tumours were entirely negative for Lewis ${ }^{y / b}$ expression using SC101 monoclonal antibody.

\section{Figure 2}

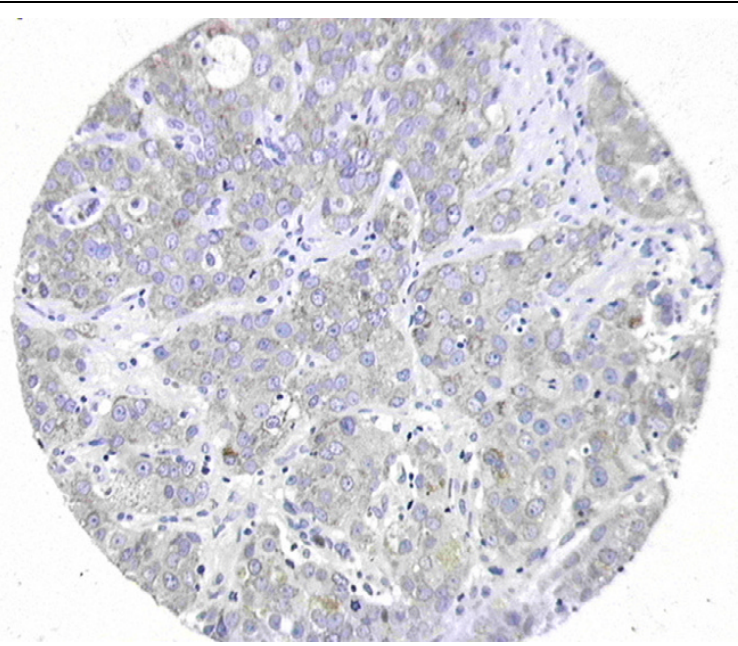

Tissue microarray core demonstrating tumour with weak Lewis ${ }^{y / b}$ expression. Seventy percent of breast tumours showed weak expression of Lewis ${ }^{/ / b}$ using SC101.

then classified into four groups as 1 ( $<25 \%$ positive cells), 2 ( $25 \%$ to $50 \%$ positive cells), 3 ( $51 \%$ to $75 \%$ positive cells) or 4 (>75\% positive cells). In addition, the histochemical score ( $\mathrm{H}$ score) of immunoreactivity was obtained by multiplying the intensity and percentage scores [15]. The histochemical scores were subgrouped into three groups of equal range for analysis, and a score of $<100$ was considered weak, 100 to 200 as moderate and 201 to 300 as strong.

\section{Statistical analysis}

Statistical analysis of data was performed using the SPSS package (version 11 for Windows; SPSS, Chicago, IL, USA). The significance of associations was determined by means of 
Figure 3

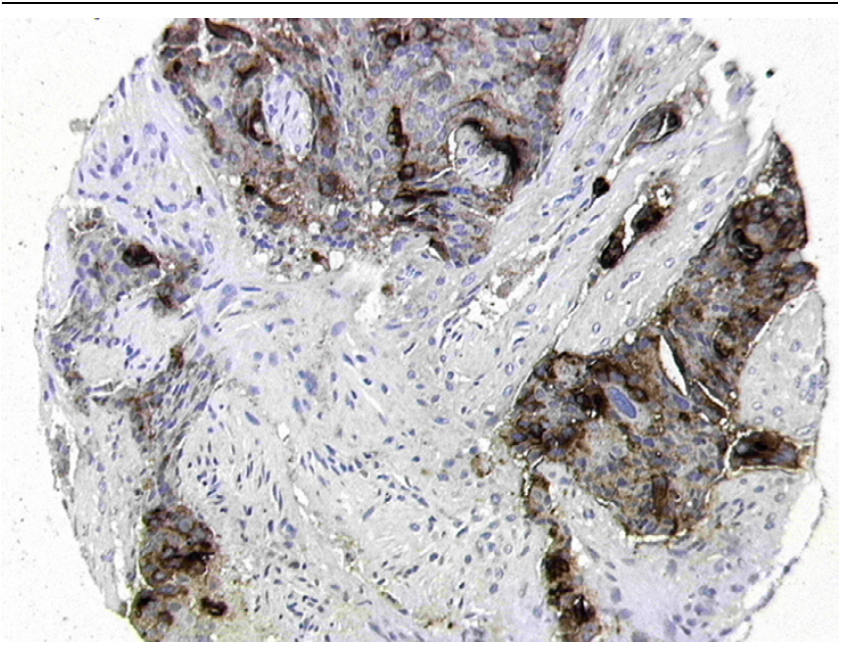

Tissue microarray core demonstrating tumour with moderate Lewis $y / b$ expression. Thirteen percent of tumours showed moderate expression of Lewisy/b.

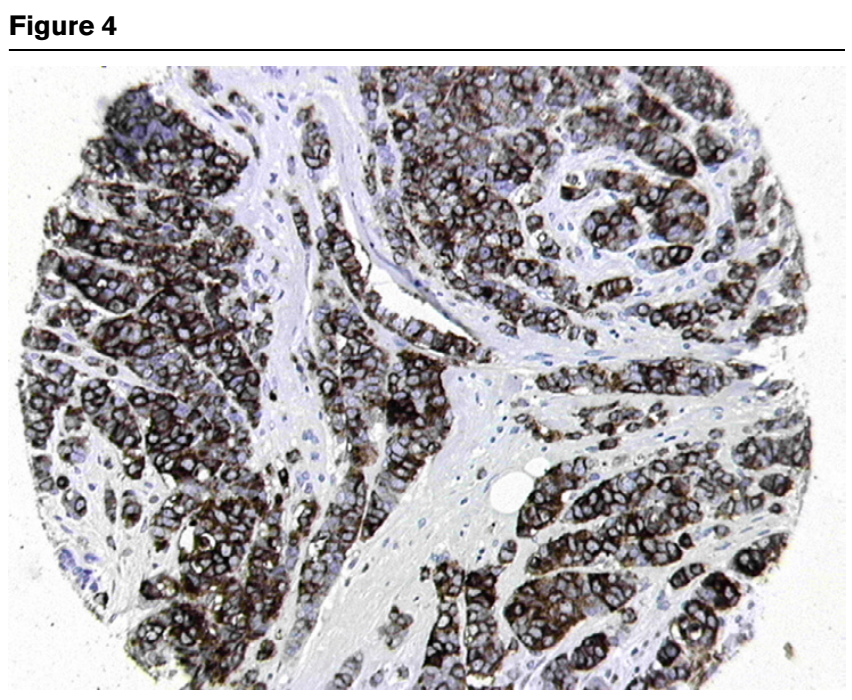

Tissue microarray core demonstrating tumour with strong Lewis $y / b$ expression. Fourteen percent of tumours demonstrated strong expression of Lewis $/ / b$.

the Pearson $\mathrm{R}$ test and/or Pearson chi-square tests. To give sizes of effect and to look at the independence of effects, the percentage of Lewis ${ }^{\mathrm{y} / \mathrm{b}}$ positive cells reclassified as a binary outcome (high, $>25 \%$ positive cells; low, $<25 \%$ positive cells) and effects of clinicopathological parameters were assessed using multiple logistic regression to give adjusted odds ratios and $95 \%$ confidence intervals.

In survival analysis, Kaplan-Meier curves were derived and the statistical significance of differences in survival between groups with different Lewisy/b expression was determined using the log-rank test. Survival was censored if the patients were still alive at the time of data analysis, or at the time of
Table 2

Percentage of cells showing immunoreactivity of SC101

\begin{tabular}{lc}
\hline Percentage of SC101 positive cells & $\%$ of tumours \\
\hline $0 \%$ (no staining) & $56(n=370)$ \\
$1 \%$ to $25 \%$ & $17(n=110)$ \\
$25 \%$ to $50 \%$ & $11(n=71)$ \\
$5 \%$ to $75 \%$ & $8(n=55)$ \\
$>75 \%$ & $8(n=54)$ \\
Total & 660
\end{tabular}

Table 3

Intensity of SC101 expression

\begin{tabular}{lc}
\hline Immunohistochemical score & $\%$ of tumours \\
\hline None & $56(n=370)$ \\
Weak & $16(n=106)$ \\
Moderate & $13(n=89)$ \\
Strong & $15(n=95)$ \\
Total & 660 \\
\end{tabular}

death for patients who died from an unrelated cause. Multivariate Cox regression analysis was used to evaluate the independent prognostic effect of variables on overall survival. $P$-values of $<0.05$ were identified as statistically significant.

\section{Results \\ Level of expression of Lewisy/b on breast carcinomas}

Of the breast carcinomas, 370 out of 660 (56\%) were entirely negative for Lewis ${ }^{y / b}$ expression (Fig. 1). A variable percentage of positively staining tumour cells was observed among the remaining 290 breast carcinomas; 110 (17\%) cases showed a low level of expression ( $<25 \%$ of positive cells) and only 54 cases (8\%) showed extensive expression of Lewis $/ / b(>75 \%$ of positive cells) on the cell membrane (Table 2). The staining observed was predominantly localised to the cell membrane and cytoplasm. No nuclear staining was observed.

Similarly, with regard to the intensity of staining, $17 \%$ (106) showed weak expression of Lewis $/ \mathrm{b}$, whereas $89(13 \%)$ and $95(14 \%)$ of cases showed moderate and strong staining, respectively (Figs 2, 3, 4; Table 3).

\section{Association of Lewis ${ }^{\mathrm{y} / \mathrm{b}}$ expression with clinicopathological characteristics}

A frequency histogram for the percentage of positive cells stained demonstrated that the mean value was $25 \%$. This was therefore chosen as an appropriate cut-off for subsequent analysis (data not shown). Tumours were therefore divided 
Table 4

\begin{tabular}{lccc} 
Association of Lewis ${ }^{\text {/b }}$ expression with clinicopathological characteristics (chi-square test) & \\
\hline Prognostic factors & Cut-off points & Intensity of staining (p-value) & Percentage of positive cells (p-value) \\
\hline Age (years; median 56) & $<40,41-50,51-60,>60$ & 0.011 & 0.014 \\
Menopausal status & Pre- or post-menopausal & 0.547 & 0.917 \\
Histological grade & Well, moderate, poor differentiated & 0.009 & $<0.001$ \\
Lymph node (LN) stage & LN -/ LN+ & 0.368 & 0.419 \\
Tumour size (mm) & $<10,11-20,21-30,31-40,41-50$ & 0.594 & 0.884 \\
Nottingham Prognostic Index & Good, moderate, or poor & 0.151 & 0.016 \\
Tumour type & $1,2,3$ or 4 & 0.093 & 0.007 \\
Vascular invasion & None or definite & 0.293 & 0.316 \\
Distant metastases & Absent or present & 0.515 & 0.532 \\
Any recurrence & Absent or present & 0.533 & 0.743 \\
Local recurrence & Absent or present & 0.775 & 0.908 \\
Regional recurrence & Absent or present & 0.314 & 0.278
\end{tabular}

\section{Table 5}

\begin{tabular}{|c|c|c|}
\hline Prognostic factors & Odds ratios $(95 \% \mathrm{Cl})$ & Test for trend (linear by linear) \\
\hline Histological grade & & $<0.001$ \\
\hline Well & 1 & \\
\hline Moderate & $1.51(0.87-2.61)$ & \\
\hline Poor & $2.50(1.51-4.16)$ & \\
\hline Nottingham Prognostic Index & & 0.016 \\
\hline Good & 1 & \\
\hline Moderate & $1.63(1.09-2.44)$ & \\
\hline Poor & $1.99(1.13-3.50)$ & \\
\hline Tumour type & & 0.007 \\
\hline Excellent & 1 & \\
\hline Good & $2.03(0.66-6.23)$ & \\
\hline Moderate & $2.25(0.701-7.25)$ & \\
\hline Poor & $3.12(1.07-9.11)$ & \\
\hline
\end{tabular}

aPositive cells were categorized into two groups, high $(<25 \%)$ and low $(>25 \%)$. Cl, confidence interval.

into those with $<25 \%$ versus those with $>25 \%$ positive cells stained based on the distribution of staining results.

A significant positive relationship was found between the percentage of Lewisy/b positive tumour cells and histological grade of invasive tumours ( $p<0.001$; Table 4 ); a higher percentage of Lewis ${ }^{y / b}$ positive tumour cells were identified more frequently in histological grade 3 tumours compared to grade 1 lesions. The odds ratio for higher percentage of Lewis ${ }^{y / b}$ in those with a poor histological grade compared with those with a well differentiated tumour was 2.509 (95\% confidence interval, 1.51 to 4.16 ) (Table 5).

A higher percentage of positive tumour cells was also identified more frequently in tumours from patients in the poor prognosis NPI group (NPI > 5.4) compared with those in the good prognosis group (NPI $\leq 3.4, \mathrm{p}<0.016$ ), with an odds ratio of 1.99 (1.13 to 3.5 ) (Table 5 ). In addition, a higher proportion of Lewis $y / b$ positive tumour cells was seen more frequently in poor prognosis tumour types (ductal/ NST (No 
Figure 5

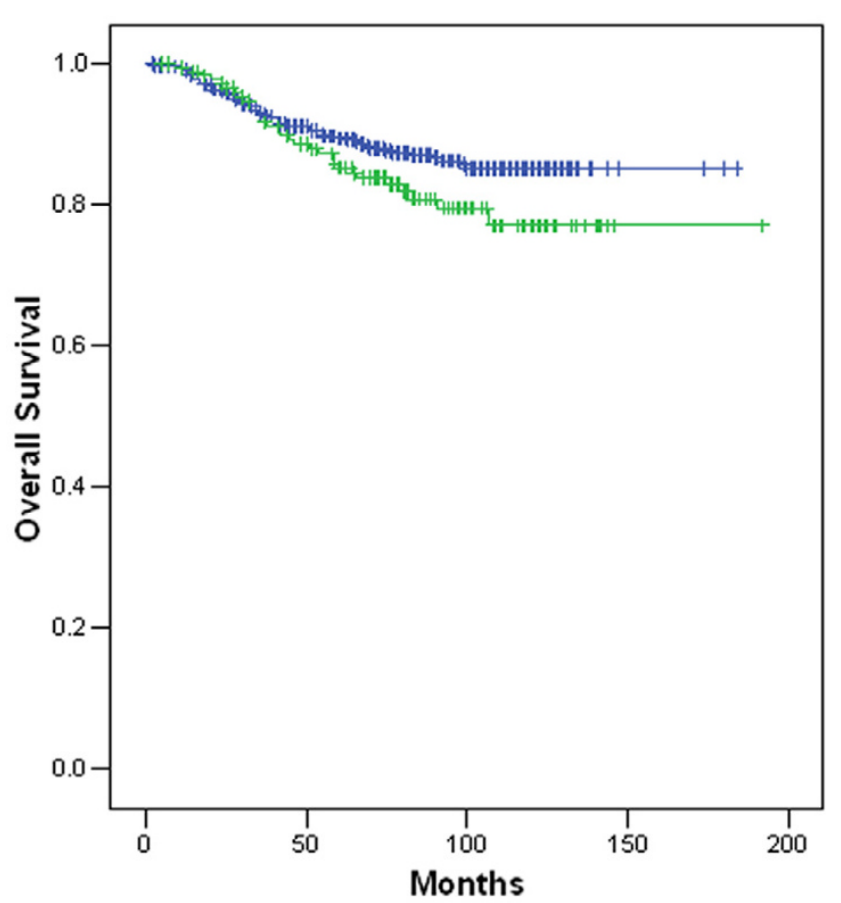

Correlation between the percentage of Lewis $\mathrm{y}^{\mathrm{b}} \mathrm{b}$ positive tumour cells and overall survival $(n=660)$. Kaplan-Meier survival analysis. Comparison of breast cancer patients with a low percentage of Lewis $/ \mathrm{b}$ positive cells (blue curve: $<25 \%$ positive cells, $n=480$ ), and patients with $>25 \%$ positive tumour cells (green curve: $n=180, p=0.091$ ).

special type)), solid lobular, lobular mixed or mixed NST and lobular cancers) compared to the excellent prognosis tumour types (tubulo-lobular, tubular, mucinous and invasive cribriform) ( $p<0.007)$, with an odds ratio of 3.12 (1.07 to 9.11) (Table 5).

There was a positive association between the observed intensity of expression of Lewis ${ }^{y / b}$ and histological tumour grade ( $p$ $=0.009$ ). No association was found, however, between intensity of expression and NPI or tumour type. Similarly, we could not find any association between either intensity of expression or the percentage of positive cells and the vascular invasion status, local recurrence, lymph node stage or menopausal status (Table 4).

\section{Survival analysis}

Kaplan-Meier analysis of this cohort of breast cancer patients, with mean follow-up of 7 years, did not demonstrate significant differences in the overall survival between patients with a low percentage of Lewis ${ }^{y / b}$ positive cells $(<25 \%)$ versus patients with $>25 \%$ positive tumour cells in the cohort as a whole (Fig. 5 ). On subgroup analysis, however, a significant correlation ( $p$ $=0.006$ ) was identified between the proportion of Lewis ${ }^{\mathrm{y}} / \mathrm{b}$ positive tumour cells and survival in lymph-node negative patients (Fig. 6). Analysis using the log-rank test showed that
Figure 6

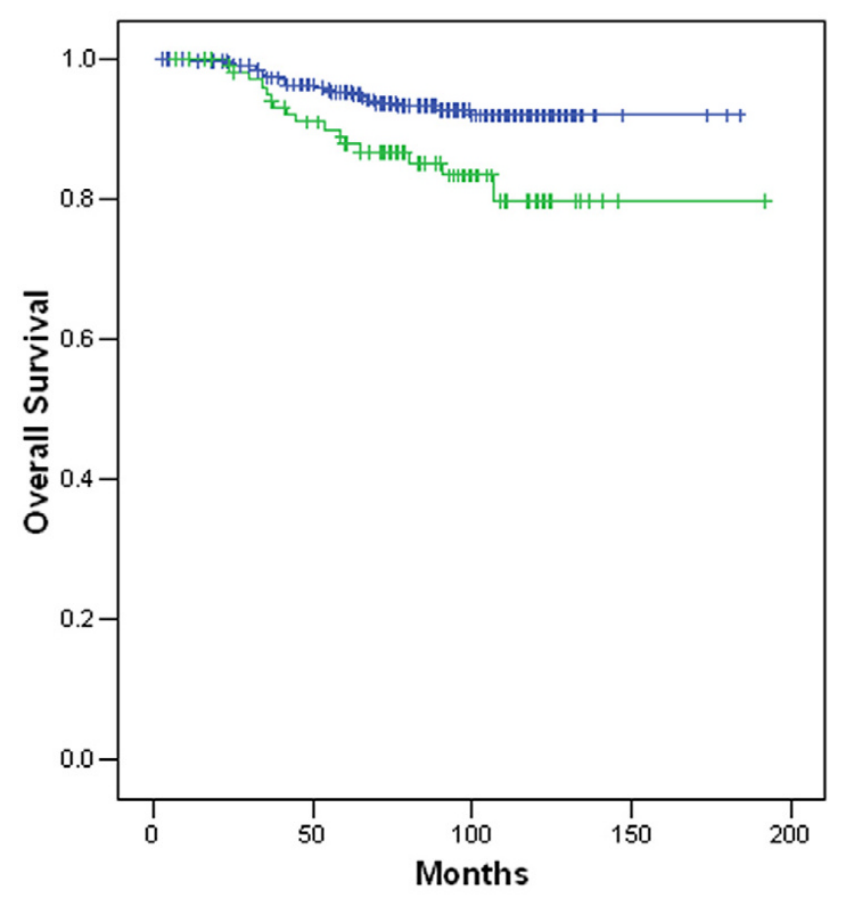

Percentage of Lewis $/ \mathrm{b}$ positive cells and overall survival in node-negative breast cancer patients $(n=430)$. Kaplan-Meier analysis showed that patients with a low percentage of Lewis ${ }^{y / b}$ positive cells (blue curve: $<25 \%$ positive cells, $n=315$ ) have significantly longer survival times than patients with $>25 \%$ positive tumour cells (green curve: $n=$ $115, p=0.006)$.

in these lymph-node negative tumours $(n=430)$, patients with a low percentage of Lewisy/b positive cells $(<25 \%$ positive cells, $n=315$ ) have significantly longer survival times than patients with $>25 \%$ positive tumour cells ( $n=115, p=$ 0.006).

In contrast, there was no significant association between the intensity of Lewis ${ }^{y / b}$ expression and overall survival between the patient group with no expression of Lewis ${ }^{y / b}$ versus positive tumours (weak, moderate or strong staining) in the cohort as a whole (log rank $=0.667$ ), or on subgroup analysis in lymph-node negative patients (log rank $=0.140$ ).

Multivariate analysis, including the factors of tumour size, nodal status, tumour grade and Lewisy/b expression showed that tumour size, tumour grade and nodal status were independent prognostic parameters, whereas Lewisy/b expression was not an independent prognostic marker in this patient cohort.

\section{Discussion}

Blood group related antigens are frequently altered in association with neoplastic transformation in many organs. This study 
illustrates the prognostic and potential predictive value of Lewisy/b expression in a large series of 660 patients with invasive breast carcinoma. Forty-four percent of cases demonstrated Lewisy/b expression, with eight percent showing extensive expression. A higher percentage of Lewisy/b expression was significantly correlated with histological grade, NPI and histological tumour type group and, in lymph-node negative patients, overall survival decreased with increasing level of Lewis ${ }^{y / b}$ expression.

There are few previous reports of blood group antigens in relation to prognosis from breast cancer. Our results are in concordance with a previous study, however, in which higher expression of Lewis ${ }^{a}$ and Lewis ${ }^{b}$ was observed in lymph node negative tumours than in lymph node positive tumours, and higher expression of Lewis ${ }^{b}$ was seen in stage T4 than in stage T1 tumours, suggesting that the expression of sialosyl-Lewis ${ }^{b}$ and Lewis a antigens in breast cancer may predict metastases to lymph nodes [16]. A positive correlation between Lewisy expression and a poor prognosis has also been shown for superficial oesophageal carcinomas [17].

Lewisy and Lewis ${ }^{b}$ are expressed on both glycolipids and glycoproteins $[6,18]$. It has been shown that an antibody, ABL364 , recognising Lewisy can inhibit Erb-B signalling by rerouting these receptors to a submembrane compartment from which they rapidly recycle to the cell surface [19]. A previous study on this series of breast tissue arrays has shown that expression of the epidermal growth factor receptor (Erb-B1) was significantly associated with a high histological grade, high NPI score, negative ER status, larger tumour size, the development of distant metastases and death from cancer. We have also demonstrated that c-erbB-2 expression independently predicted for poor overall survival in this population of breast cancer patients [20]. There was no association, however, between Erb-B1 expression and Lewisy expression in this group of tumours.

Lewisy can be up-regulated in response to cellular stress. Indeed, up-regulation of Lewisy in response to chemotherapeutic stress, and in particular to the chemotherapeutic agent 5 -fluorouracil, has been previously reported [21]. In early stage breast cancer, expression of Lewisy/b may, therefore, be a marker of aggressive or stressed tumours.

A range of Lewisy antibodies have been identified, but these consistently cross react with Lewis ${ }^{\mathrm{x}}$ and $\mathrm{H}$ type 2 structures. This can lead to undesirable cross reactivity with normal tissues and subsequent toxicity in clinical trials. In a phase I study of the murine BR55-2 anti-Lewisy antibody, which cross reacts with $\mathrm{H}$ antigen in breast cancer patients, haematuria occurred in 6/12 patients and diarrhoea in $2 / 9$ patients, with only transient reductions in skin lesions seen in 3 patients [22]. A chimeric BR-96-doxorubicin conjugate has also been evaluated in patients with a range of advanced cancers. BR-96 cross- reacts with $B$ hapten and gastrointestinal binding was found to be dose limiting [23]. Finally, the Lewisy specific humanised antibody 35193 has shown good selectivity in binding studies and is about to enter phase I clinical trials [24]. Lewisy has also been suggested as a target for cancer vaccines; however, immunising with synthetic Lewisy generated carbohydrate specific antibodies but they failed to bind to tumour cells. In contrast, MMA383 is an anti-idiotypic antibody that mimics Lewisy and stimulates good antibody responses. It has been humanised [25] and will shortly enter clinical trials.

\section{Conclusion}

Analysis of Lewisy/b expression in early stage breast cancer patients may aid selection of patients for more aggressive chemotherapy, as tumours with a high percentage of cells expressing Lewisy/b appear to have a significantly greater chance of disease progression. This may also eventually allow stratification of patients for mAb therapy directed against these carbohydrate antigens; however, specific antibodies that directly induce cell killing but do not cross react with $\mathrm{H}$ or B blood groups first need to be selected. SC101/29 is a promising candidate and is currently being humanised for clinical trials.

\section{Competing interests}

The authors declare that they have no competing interests.

\section{Authors' contributions}

ZM and NFSW carried out the immunohistochemistry, scored the staining, analyzed the data and drafted the manuscript. TP made the SC101 primary antibody. LGD, IOE and IS designed the study and provided the tissue microarray. All authors were responsible for interpreting the results and drafting the article. All authors read and approved the final manuscript.

\section{Acknowledgements}

The authors thank Mrs Claire Paish and Mr John Ronan for their technical advice. This work was supported by a grant from the CRUK.

\section{References}

1. Wiley EL, Mendelsohn G, Eggleston JC: Distribution of carcinoembryonic antigens and blood group substances in adenocarcinoma of the colon. Lab Invest 1981, 44:507-513.

2. Inoue $M$, Nakayama M, Tanizawa O: Altered expression of Lewis blood group and related antigens in fetal, normal adult and malignant tissues of the uterine endometrium. Virchows Arch A Pathol Anat Histopathol 1990, 416:221-228.

3. Inoue M, Sasagawa T, Saito J, Shimizu H, Ueda G, Tanizawa O, Nakayama M: Expression of blood group antigens A, B, H, Lewis-a, and Lewis-b in fetal, normal, and malignant tissues of the uterine endometrium. Cancer 1987, 60:2985-2993.

4. Dettke M, Palfi G, Loibner H: Activation-dependent expression of the blood group-related lewis $Y$ antigen on peripheral blood granulocytes. J Leukoc Biol 2000, 68:511-514.

5. Hellstrom I, Garrigues HJ, Garrigues U, Hellstrom KE: Highly tumor-reactive, internalizing, mouse monoclonal antibodies to Le(y)-related cell surface antigens. Cancer Res 1990, 50:2183-2190.

6. Basu A, Murthy U, Rodeck U, Herlyn M, Mattes L, Das M: Presence of tumor-associated antigens in epidermal growth factor receptors from different human carcinomas. Cancer Res 1987, 47:2531-2536. 
7. Durrant LG, Singhal A, Jacobs E, Price MR: Development of second generation monoclonal antibodies recognising Lewisy/b antigen by anti-idiotypic immunisation. Hybridoma 1993, 12:647-660.

8. Elston CW, Ellis IO: Pathological prognostic factors in breast cancer. I. The value of histological grade in breast cancer: experience from a large study with long-term follow-up. Histopathology 1991, 19:403-410.

9. Ellis IO, Galea M, Broughton N, Locker A, Blamey RW, Elston CW: Pathological prognostic factors in breast cancer. II. Histological type. Relationship with survival in a large study with longterm follow-up. Histopathology 1992, 20:479-489.

10. Pinder SE, Ellis IO, Galea M, O'Rouke S, Blamey RW, Elston CW: Pathological prognostic factors in breast cancer. III. Vascular invasion: relationship with recurrence and survival in a large study with long-term follow-up. Histopathology 1994, 24:41-47.

11. Todd JH, Dowle C, Williams MR, Elston CW, Ellis IO, Hinton CP, Blamey RW, Haybittle JL: Confirmation of a prognostic index in primary breast cancer. Br J Cancer 1987, 56:489-492.

12. Galea MH, Blamey RW, Elston CE, Ellis IO: The Nottingham Prognostic Index in primary breast cancer. Breast Cancer Res Treat 1992, 22:207-219.

13. Kononen J, Bubendorf $L$, Kallioniemi A, Barlund M, Schraml P, Leighton S, Torhorst J, Mihatsch MJ, Sauter G, Kallioniemi OP: Tissue microarrays for high-throughput molecular profiling of tumor specimens. Nat Med 1998, 4:844-847.

14. Madjd Z, Durrant LG, Bradley R, Spendlove I, Ellis IO, Pinder SE: Loss of CD55 is associated with aggressive breast tumors. Clin Cancer Res 2004, 10:2797-2803.

15. McCarty KS Jr, Miller LS, Cox EB, Konrath J, McCarty KS Sr: Estrogen receptor analyses. Correlation of biochemical and immunohistochemical methods using monoclonal antireceptor antibodies. Arch Pathol Lab Med 1985, 109:716-721.

16. Steplewska-Mazur K, Gabriel A, Zajecki W, Wylezol M, Gluck M: Breast cancer progression and expression of blood grouprelated tumor-associated antigens. Hybridoma 2000, 19:129-133.

17. Tauchi K, Kakudo K, Machimura T, Makuuchi H, Mitomi T: Immunohistochemical studies of blood group-related antigens in human superficial esophageal carcinomas. Cancer 1991, 67:3042-3050.

18. Garrigues J, Anderson J, Hellstrom KE, Hellstrom I: Anti-tumor antibody BR96 blocks cell migration and binds to a lysosomal membrane glycoprotein on cell surface microspikes and ruffled membranes. J Cell Biol 1994, 125:129-142.

19. Klinger $M$, Farhan $H$, Just $H$, Drobny $H$, Himmler $G$, Loibner $H$, Mudde GC, Freissmuth M, Sexl V: Antibodies directed against Lewis-Y antigen inhibit signaling of Lewis-Y modified ErbB receptors. Cancer Res 2004, 64:1087-1093.

20. Abd El-Rehim DM, Pinder SE, Paish CE, Bell JA, Rampaul RS, Blamey RW, Robertson JF, Nicholson RI, Ellis IO: Expression and co-expression of the members of the epidermal growth factor receptor (EGFR) family in invasive breast carcinoma. $\mathrm{Br} J$ Cancer 2004, 91:1532-1542.

21. Flieger D, Hoff AS, Sauerbruch T, Schmidt-Wolf IG: Influence of cytokines, monoclonal antibodies and chemotherapeutic drugs on epithelial cell adhesion molecule (EpCAM) and LewisY antigen expression. Clin Exp Immunol 2001, 123:9-14.

22. Tolcher AW, Sugarman S, Gelmon KA, Cohen R, Saleh M, Isaacs C, Young L, Healey D, Onetto N, Slichenmyer W: Randomized phase II study of BR96-doxorubicin conjugate in patients with metastatic breast cancer. J Clin Oncol 1999, 17:478-484.

23. Saleh MN, Sugarman S, Murray J, Ostroff JB, Healey D, Jones D, Daniel $\mathrm{CR}$, LeBherz $\mathrm{D}$, Brewer $\mathrm{H}$, Onetto $\mathrm{N}$, et al: Phase I trial of the anti-Lewis $Y$ drug immunoconjugate BR96-doxorubicin in patients with lewis Y-expressing epithelial tumors. J Clin Oncol 2000, 18:2282-2292.

24. Scott AM, Geleick D, Rubira M, Clarke K, Nice EC, Smyth FE, Stockert E, Richards EC, Carr FJ, Harris WJ, et al: Construction, production, and characterization of humanized anti-Lewis $Y$ monoclonal antibody 3S193 for targeted immunotherapy of solid tumors. Cancer Res 2000, 60:3254-3261.

25. Co MS, Baker J, Bednarik K, Janzek E, Neruda W, Mayer P, Plot R, Stumper B, Vasquez M, Queen C, et al:: Humanized anti-Lewis $Y$ antibodies: in vitro properties and pharmacokinetics in rhesus monkeys. Cancer Res 1996, 56:1118-1125.
26. Pereira $H$, Pinder SE, Sibbering DM, Galea MH, Elston CW, Blamey RW, Robertson JF, Ellis IO: Pathological prognostic factors in breast cancer. IV: Should you be a typer or a grader? A comparative study of two histological prognostic features in operable breast carcinoma. Histopathology 1995, 27:219-226. 